\title{
Does perceived angular declination contribute to perceived optical slant on level ground?
}

\author{
Zhi Li ${ }^{1}$ Frank H. Durgin ${ }^{2}$ \\ Published online: 31 May 2018 \\ (C) The Psychonomic Society, Inc. 2018
}

\begin{abstract}
When one looks at a spot on level ground, the local optical slant (i.e., surface orientation relative to the line of sight) is geometrically equivalent to the angular declination (i.e., sagittal visual direction relative to horizontal). In theory, angular declination provides an unbiased proximal source of information for estimating optical slant on level ground. Two experiments were conducted to investigate whether human visual systems take advantage of this information. An aspect ratio task was used as an implicit measure for assessing perceived optical slant. Participants gave verbal estimates of the perceived aspect ratio of an Lshaped arrangement, formed by three balls on level ground or on slanted surfaces (hills). Gaze direction was held horizontal when viewing the stimuli on hills. Experiment 1 examined two optical slants $\left(22^{\circ}\right.$ to $\left.35^{\circ}\right)$ at relatively short viewing distances $(3.1$ to $11.5 \mathrm{~m}$ ), while Experiment 2 tested a shallow optical slant $\left(6^{\circ}\right)$ at relatively long viewing distances $(5.7$ to $17.2 \mathrm{~m})$. No significant difference in perceived aspect ratio was found between the level-ground and the hill conditions in either experiment. These findings suggest that angular declination does not contribute to perceived optical slant on level ground. It seems that the perception of optical slant and of gaze declination are independent, and this may be because the two variables are normally used jointly to determine a higher order perceptual variable — geographical slant.
\end{abstract}

Keywords Optical slant $\cdot$ Geographical slant $\cdot$ Angular declination $\cdot$ Scale expansion hypothesis $\cdot$ Aspect ratio

Perception of surface orientation is fundamental to vision because objects are covered by surfaces. As Gibson (1950) pointed out, visual information of the environment is provided in the form of dynamic optical array, which is determined by all the visible surfaces in the environment (see also Sedgwick, 1986). The orientation of a surface relative to the line of sight of the observer is called optical slant (Gibson \& Cornsweet, 1952). It has been shown that visual cues, such as texture gradient and binocular disparity gradient, contribute to perceived optical slant (Cutting \& Millard, 1984; Li \& Durgin, 2013). In the present study, we consider another potential source of information concerning optical slant: angular declination. Whereas angular declination has been demonstrated as a powerful cue for perceived egocentric distance in locomotor space (i.e., about 2 to $20 \mathrm{~m}$; Li, Phillips, \&

Frank H. Durgin

fdurgin1@swarthmore.edu

1 Department of Psychology and Behavioral Sciences, Zhejiang University, Hangzhou, China

2 Department of Psychology, Swarthmore College, Swarthmore, PA, USA
Durgin, 2011; Messing \& Durgin, 2005; Ooi, Wu, \& He, 2001; Wallach \& O’Leary, 1982; Williams \& Durgin, 2015), it, theoretically, may also be an excellent source of information for judging optical slant on level ground, because optical slant on level ground is geometrically equivalent to the angular declination (see Fig. 1). Compared with binocular disparity cue and texture gradients, angular declination appears to be a simpler cue, and it should be perceived more robustly across different viewing conditions. For example, perceived angular declination should be less affected by viewing distance, acuity, and ocularity (i.e., viewing with one eye or with two eyes). For this reason, angular declination appears to be an excellent source of perceptual information concerning optical slant along level ground. Moreover, it has been reported that perceived geographical slant (e.g., the slope of a hill) can be strongly affected by ocularity (Gibson \& Cornsweet, 1952) and viewing distance (Bridgeman \& Hoover, 2008; Li \& Durgin, 2010). Would these effects be mitigated somewhat for perceptual estimates of optical slant on level ground, given that participants could use perceived angular declination to estimate optical slant on level ground?

Apart from local optical slant based on texture gradients and binocular disparity, what other evidence might an 


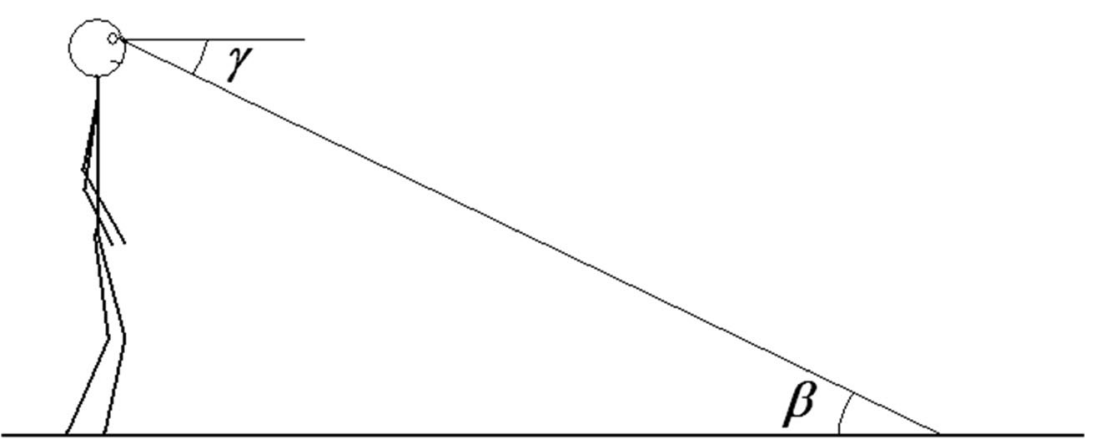

Fig. 1 Optical slant, $\beta$, on level ground is geometrically equivalent to the angular declination, $Y$

observer have that a ground surface is, in fact, level (i.e., horizontal)? For one thing, ground surfaces that humans normally confront, including outdoor environments, tend to be horizontal, so that the Bayesian prior should greatly weight the perception of level ground when image data do not rule it out. The perceptual exaggeration of perceived hill slant can be understood as being useful as a form of deviation coding (Durgin, Hajnal, Li, Tonge, \& Stigliani, 2010a), but the assumption of near-to-level ground in the absence of strong evidence to the contrary seems reasonable on statistical grounds (e.g., Adams et al., 2016). Second, there are binocular processes that have been supposed to be relevant to detecting a large-scale level-ground plane, such as the observation that the empirical horopter may lie along the ground plane when gaze is forward and fixation is at infinity (Tyler, 1991; von Helmholtz, 1866), providing a basis for an observer to detect deviations from planarity and from the horizontal. In principle, the binocular detection of planarity over a large area (e.g., Rogers \& Bradshaw, 1993) might also contribute to the ability of the visual system to generalize from near space to farther space on a level-ground plane when the ground is continuous (see also Wu, Ooi, \& He, 2004). Thus, there are many reasons to suspect that human observers would have additional evidence about the orientation of a continuous level ground surface that, combined with angular declination information, could be more accurate and more precise than the local measurement of optical slant. In this situation, using angular declination as an additional source of information about local optical slant on a level ground surface might improve or refine estimates of optical slant.

The goal of the present study is to examine whether angular declination contributes to perceived optical slant on level ground. In the literature, several methods have been used to assess perceived slant, such as verbal estimation (e.g., Proffitt, Bhalla, Gossweiler, \& Midgett, 1995), 2-D orientation matching (e.g., Li \& Durgin, 2009), palm-board gesturing (e.g., Proffitt et al., 1995), free-hand gesturing (e.g., Li \& Durgin, 2011), and aspect ratio estimation (e.g., Li \& Durgin, 2010). We decided to avoid explicit methods of slant estimation, such as verbal estimation, which is susceptible to strategies, and to avoid visual, haptic or proprioceptive matching, which are known to have biases of their own (e.g., Durgin, Hajnal, et al., 2010a; Durgin \& Li, 2011a; Li \& Durgin, 2012; Shaffer, McManama, Swank, Williams, \& Durgin, 2014). These were deemed unsuitable for the present study because using angular declination to explicitly judge optical slant on level ground could be an explicit strategy. Instead, we chose the aspect ratio task, because it acts as an implicit measure of perceived optical slant.

An aspect ratio task involves a judgment of perceived shape (i.e., perceived aspect ratio of an L-shaped configuration). The idea of using perceived shape to assess perceived slant can be traced back to Koffka (1935), who first assumed an invariant link between apparent shape and apparent slant. Beck and Gibson (1955) followed Koffka's idea and came up with a more restricted assumption, that is, "a retinal projection of a given form determines a unique relation of apparent shape to apparent slant," which is known as the shape-slant invariance hypothesis. As predicted by the shape-slant invariance hypothesis, induction of biases in perceived slant (e.g., under impoverished viewing conditions) would introduce bias in perceived shape (e.g., Beck \& Gibson, 1955; Epstein, Bontrager, \& Park, 1962). Conversely, misperception of shape may also reflect bias in perceived slant. Li and Durgin (2010) showed, using high-fidelity virtual reality, that aspect ratios on geographical slants (i.e., hills) were misperceived. The bias in perceived aspect ratio was highly consistent with the bias in explicitly estimated geographical slant measured in the same virtual environment using verbal estimation. They also reported that a slant model based on their aspect ratio data could quantitatively explain slant exaggeration of real hills reported in classic verbal data (i.e., that of Proffitt et al., 1995). According to Li and Durgin, if the aspect ratio stimuli with an actual in-depth to frontal ratio, $R$, is presented on a surface with an actual optical slant, $\beta$, then the apparent optical slant, $\beta^{\prime}$, can be obtained from the apparent aspect ratio $R^{\prime}$ (Equation 1; refer to Li \& Durgin, 2010, for detailed mathematical deduction):

$\beta^{\prime}=\sin ^{-1}\left(\frac{R}{R^{\prime}} \sin \beta\right)$. 
Another piece of evidence suggesting that perceived aspect ratio depends on optical slant was reported by Loomis and Philbeck (1999; see also Loomis, Philbeck, \& Zahorik, 2002), who observed that, for the same physical aspect ratio, bias in the perceived ratio was greater when viewed monocularly than when viewed binocularly. This finding in perceived aspect ratio is consistent with the result in perceived slantperceived slant is also more biased in monocular viewing conditions (the frontal tendency; Gibson \& Cornsweet, 1952). Moreover, Loomis and Philbeck (1999) also found that bias in perceived aspect ratio was scale invariant in monocular viewing conditions (i.e., perceived aspect ratio was not affected by viewing distance when viewed with one eye). This is also consistent with monocularly perceived slant, which is mostly determined by texture cues.

Studies of perceived ground extents at increasing distances were originally used to suggest that perceived ground distance is increasingly compressed with distance (e.g., Gilinsky, 1951). However, with observers at a constant eye height, distance and optical slant are normally confounded in these studies, as noted by Loomis and Philbeck (1999). We gathered together data from aspect ratio tasks reported in seven different studies involving 11 different groups of participants all tested in well-lit, natural environments (see Table 1). We computed the mean physical aspect ratios (sagittal/frontal) that appear as 1:1 ratios, for each cell of each experiment (a total of 128 data points), including only binocular conditions, except when the viewing surface was a table (very near space). These values are plotted as a function of optical slant (see Fig. 2a) and as a function of viewing distance (Fig. 2b), breaking out the data that differed in eye height (which breaks the correlation between viewing distance and optical slant) or ocularity. Consistent with the model of Li and Durgin (2010), these data (particularly those that manipulate eye height) show that bias in perceived aspect ratio is tightly correlated with optical slant while only secondarily affected by viewing distance. For example, raising the eye height, while controlling for optical slant, seems to increase the ratios slightly - as a function of increased viewing distance (see Fig. 2a). But when plotted with respect to viewing distance (Fig. 2b), increased eye height (and thus increased optical slant) decreases the bias in ratios substantially, which is clearly a result of the increased optical slant while controlling for viewing distance (Fig. 2b).

Because the purpose of the present study is to investigate whether angular declination may contribute to perceived optical slant on level ground, Experiment 1 compared perceived aspect ratios on level ground with perceived aspect ratios on hill surfaces. Optical direction to the target was horizontal in the hill surface condition, so that angular declination provided no information about the actual optical slant. The viewing distance, ocularity (all participants viewed the scene binocularly) and optical slant were matched across the different surfaces (hill or level ground). Whereas there were empirical data on perceived aspect ratio on level ground, to our knowledge, perceived aspect ratio on slanted surfaces has not been studied in real environments.

\section{Experiment 1}

\section{Method}

Participants Sixteen undergraduate students from Swarthmore College participated in this experiment for payment. This is twice the modal number tested in the studies summarized in Fig. 2. All the participants had normal or corrected-to-normal vision and were not made aware of the hypotheses under

Table 1 Data used in constructing Fig. 2

\begin{tabular}{|c|c|c|c|c|c|}
\hline Source experiment & $N$ & Eye height & Surface & Ocularity & Unique cells $^{\mathrm{a}}$ \\
\hline Beusmans (1998), Expt. 2 & 8 & Normal & Grass & Binocular & 35 \\
\hline Kudoh (2005), Expt. 1 & 10 & Normal & Grass & Binocular & 30 \\
\hline Loomis et al. (1992), Expt. 1 & 10 & Normal & Grass & Binocular & 15 \\
\hline Loomis et al. (1992), Expt. 2 & 10 & Normal & Grass & Binocular & 15 \\
\hline Loomis \& Philbeck (1999) & 8 & Normal & Grass & Binocular & 6 \\
\hline Loomis \& Philbeck (1999) & 8 & Raised (5.85 m) & Grass & Binocular & 6 \\
\hline Loomis et al. (2002), Expt. 1 & 8 & Normal & Floor & Binocular & 3 \\
\hline Loomis et al. (2002), Expt. 1 & 8 & Lowered $(0.18 \mathrm{~m})$ & Table & Binocular & 3 \\
\hline Loomis et al. (2002), Expt. 1 & 8 & Lowered $(0.18 \mathrm{~m})$ & Table & Monocular & 3 \\
\hline Loomis et al. (2002), Expt. 2 & 8 & Lowered $(0.41 \mathrm{~m})$ & Table & Binocular & 3 \\
\hline Loomis et al. (2002), Expt. 2 & 8 & Lowered $(0.41 \mathrm{~m})$ & Table & Monocular & 3 \\
\hline Philbeck (2000), Expt. 1 & 11 & Normal & Floor & Binocular & 3 \\
\hline Wu et al. (2004), Expt. 2 & 10 & Normal & Grass & Binocular & 3 \\
\hline
\end{tabular}

${ }^{\text {a }}$ Represents the number of unique combinations of extent sizes and viewing distances 

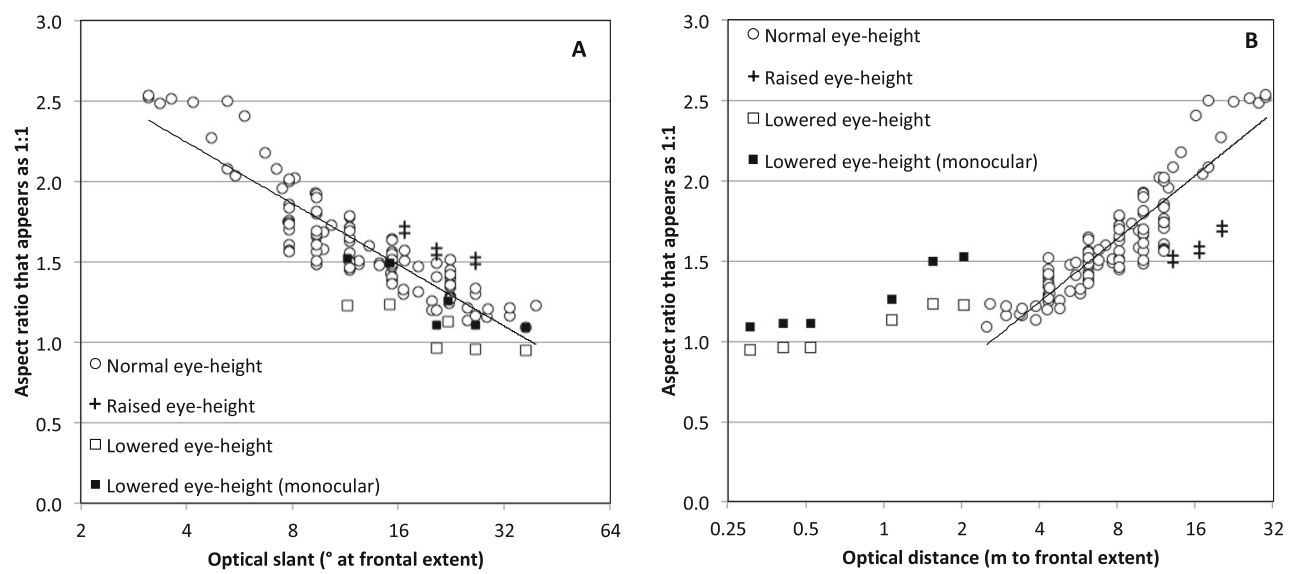

Fig. 2 Graphic summary of the results of the studies listed in Table 1. The physical aspect ratio perceived as 1:1 is plotted as a function of optical slant (a) and as a function of viewing distance (b) for all the aspect ratio data in Table 1. Eye heights from 1.5 to $2.0 \mathrm{~m}$ are considered "normal"

consideration. The experimental procedures reported in this article were approved by the local research ethics committee.

Environments The experiment was conducted in three outdoor fields located in the campus of Swarthmore College, including two hills and a level open field with a large bleacher nearby, which allowed us to manipulate optical slant and viewing distance independently. All the fields were covered with lawn. The aspect ratio stimuli were composed of three white foam balls arranged in an $\mathrm{L}$ shape. The size of the ball was scaled to viewing distance, with a fixed angular size of $0.6^{\circ}$. The size of the frontal extent of the $\mathrm{L}$ shape was also scaled to viewing distance, with a fixed angular size of $7.2^{\circ}$. There were two testing conditions: the hill condition and the level-ground condition. In the hill condition, the balls were laid on the surface of a hill, with the corner ball being at eye level (see Fig. 3a). Two hills were used. One had an inclination of $22^{\circ}$ and the other of $35^{\circ}$. Both were approximately planar in the testing area. Two viewing distances were tested for each hill. For the $22^{\circ}$ hill, the distances were 6 and $11.5 \mathrm{~m}$. For the $35^{\circ}$ hill, the distances were 3.1 and $7.5 \mathrm{~m}$. For the hill conditions, the eye height of the observers from the level ground on which they stood was held at $1.8 \mathrm{~m}$, using an adjustable pile of rigid pads. In the level-ground condition, the balls were laid on a level ground, and the participants stood either on the ground or on the stairs of a bleacher (see Fig. 3b). The optical slant and viewing distance in the ground condition matched those in the hill condition for each participant. Pads were again used, as necessary, to match the intended viewing points for each target.

Procedure Participants were tested in the two surface conditions in separate blocks. Half of the participants performed the hill condition first, the other half performed the level-ground condition first. The order of the four (Distance $\times$ Slant) combinations were randomized in each block. For each of the
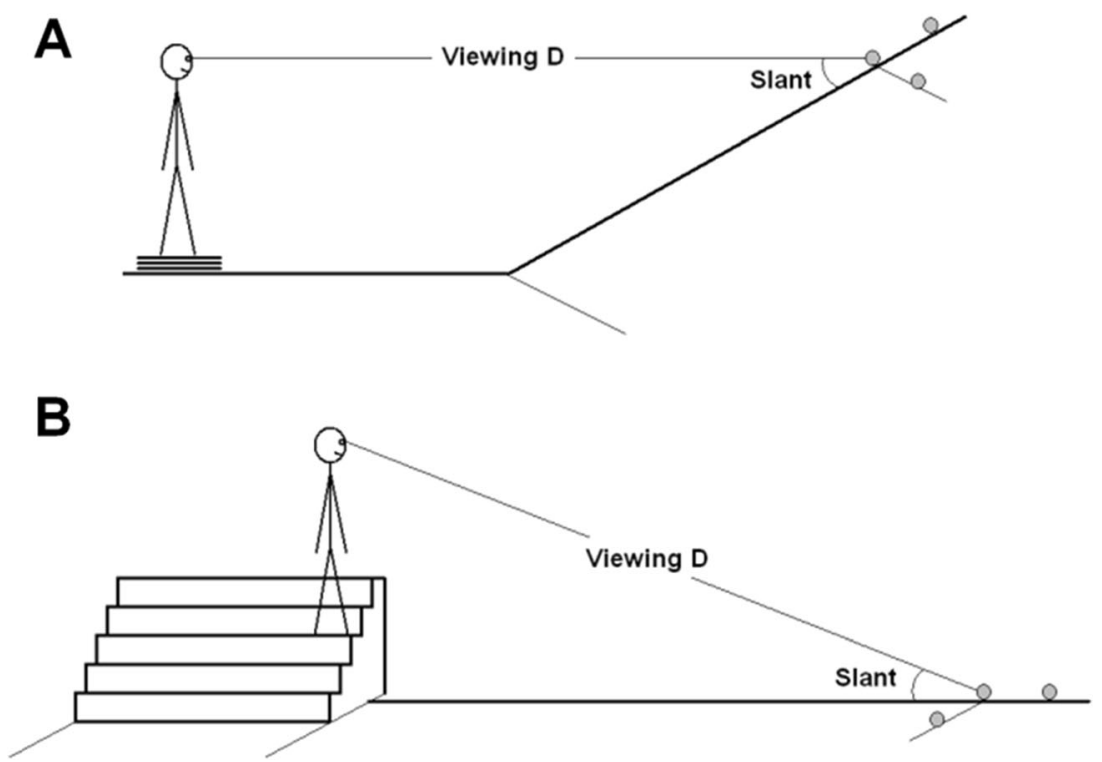

Fig. 3 Diagram depicting the environments used in Experiment 1. a Setup in the hill condition. b Setup in the level-ground condition 
combinations, four trials were conducted for each participant. In the first two trials, the physical aspect ratio of the L-shaped configuration (in-depth/frontal) was either 0.5 or 2.5 , in a random order. The participant's task was to give numeric estimates of the perceived aspect ratio in each trial. Their estimates were immediately used to calculate the physical ratio that would be perceived as 1:1 by the participants (the mean reciprocal of the ratio of aspect ratio in the first two trials, following Loomis \& Philbeck, 1999). The calculated ratio was then used as the physical stimuli ratio in the third trial. After the third estimate was collected, the estimates of all three trials were then used once more to calculate the physical ratio that would be perceived as $1: 1$, which then served as the stimuli ratio for the fourth trial. This method was intended to collect data near the perceived unity point. Although the modal response was " $1: 1$ " on the third trial, most responses (59\%) still differed from 1.0, with a mean (unsigned) deviation of 0.11 overall. Even at the fourth trial, $47 \%$ differed from 1.0, with a mean deviation of 0.08 . The experiment normally lasted 45 minutes for each participant.

\section{Results}

The ratio between the actual aspect ratio and the reported ratio was computed for each trial, and averaged across the four trials collected for each participant for each testing condition. Note that this ratio of aspect ratios (RAR) is the reciprocal of the measure used by Loomis and Philbeck (1999). The mean RARs across participants are plotted for the eight (Distance $\times$ Slant $\times$ Surface) testing conditions separately in Fig. 4 (top panel). The mean RAR varied across the different slantdistance combinations, but there is no apparent effect of the surface condition (i.e., level ground vs. hill). A within-subjects analysis of variance (ANOVA) was conducted on the complete RAR data. Factors were surface type (level ground or hill), optical slant $\left(22^{\circ}\right.$ or $\left.35^{\circ}\right)$, and viewing distance (near or far). Reliable main effects in the expected directions were found for optical slant, $F(1,15)=77.3, p<.001, \eta^{2}=0.691$, and for viewing distance, $F(1,15)=10.8, p=.005, \eta^{2}=0.063$. No main effect was found for the surface type, $F(1,15)=2.01$, $p=.177, \eta^{2}=0.018$.

Because each participant participated in both the hill and the level-ground conditions, it seemed important to ensure that the null finding in surface condition was not due to the contamination between the two conditions. We therefore analyzed the data from the first block alone. In this way, the design becomes between subjects. The result is shown in Fig. 4 (bottom panel), which is similar to the overall results (i.e., Fig. 4, top panel). An ANOVA was used to analyze the data. The surface condition becomes a between-subjects variable, while slant and distance remained within-subjects variables. A significant main effect was found for slant, $F(1,14)=60.7, p<$ $.001, \eta^{2}=.559$, and for distance, $F(1,14)=6.36, p=.024, \eta^{2}=$
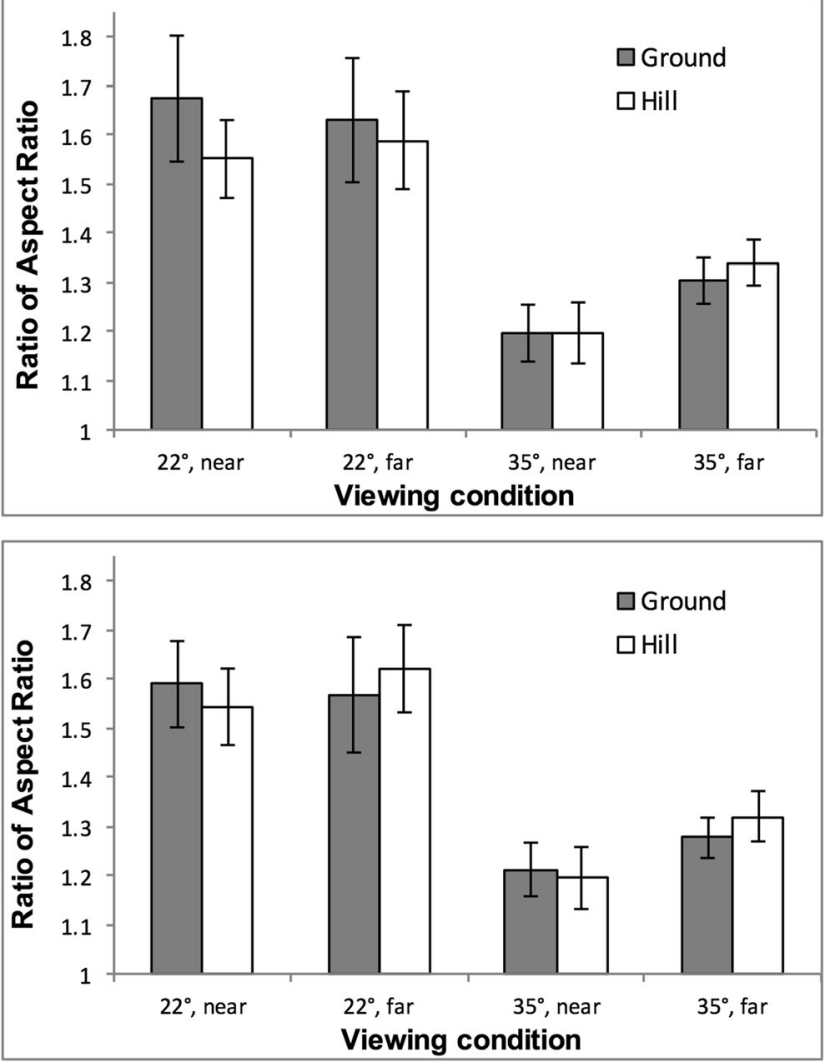

Fig. 4 Results of Experiment 1. Mean RAR (physical ratio/estimated ratio) across all the participants is plotted for each of the eight surfaceslant-distance combinations. Top panel shows the overall results. Bottom panel shows that of the first block only, where hill and level ground conditions represent between-subject comparisons. Error bars represent $95 \%$ confidence intervals

.042; but no significant effect of surface condition was found, $F(1,14)=0.02, p=.882, \eta^{2}<.001$.

\section{Discussion}

As we have proposed in the introduction, perceived optical slant on level ground may be determined by angular declination. Experiment 1 showed that, whereas perceived aspect ratio depends on both optical slant and viewing distance, there is no difference in the ratio of aspect ratio (physical ratio/ estimated ratio) whether the stimuli was presented on level ground or on a hill surface. There are two possible explanations to account for the present findings: (1) Angular declination does not contribute to the perception of optical slant on level ground; (2) the function relating perceived angular declination to actual declination is the same as that relating perceived to actual optical slant on the level ground (perhaps due to long-term association). Durgin and Li (2011b) showed that perceived angular declination is almost linearly exaggerated, with an angular gain of 1.5 in the range from $0^{\circ}$ to $50^{\circ}$. In contrast, perceived optical slant can be determined by actual aspect ratio and perceived aspect ratio using Equation 1 
(following Li \& Durgin, 2010, Equation 5). We thus calculated the angular gain in perceived optical slant from the aspect ratio data of Experiment 1 (the ratio of aspect ratio is used as an approximation of the physical ratio to be perceived as 1:1 ratio). The mean angular gain across the four tested slantdistance combinations is 1.52 in the level-ground condition and is 1.49 in the hill condition, which is pretty similar to the 1.5 angular gain of the perceived angular declination observed in previous studies (Durgin \& Li, 2011b; Li \& Durgin, 2009). This result apparently supports the possibility that the perceptual gain of angular declination might be essentially the same as that of perceived optical slant. If this is the case, then we would not expect to see differences in means between the hill and ground-plane conditions, but only in the precision estimates; but our procedure was not designed to measure precision.

For this reason, we decided to investigate whether there was a distance effect in perceived slant on level ground. The distance effect of perceived slant has been demonstrated mostly in geographical slant (i.e., surface slant relative to true horizontal; Bridgeman \& Hoover, 2008; Li \& Durgin, 2010, 2013). Would the effect of distance be lessened for perceived optical slant along level ground? Li and Durgin (2010; see also Li \& Durgin, 2013) suggested that the distance effect on perceived slant is more salient for shallow slants. In their data obtained from perceived aspect ratios on virtual hills, the distance effect was more salient for the $6^{\circ}$ slant than for the $24^{\circ}$ slant.

Indeed, it is possible to compute the implied perceived slant for each of the previously reported data points we plotted in Fig. 2. To do this, we simply compute the arcsin of the projected sagittal/frontal ratio that is perceived as being equilateral. A plot of these inferred perceived slant values against the true slant values is shown in Fig. 5, along with lines representing both the actual slant and slant values of 1.5 times the actual slant. In this plot it is evident that the historical data depart most clearly from a 1.5 gain in implied perceived slant for smaller optical slants.

Based on these considerations, in Experiment 2 we sought to compare hills and level ground with a shallow optical slant viewed at a typical viewing distance for level ground, and we also sought to examine the effect of viewing distance with an aspect ratio task conducted on level ground, varying eye height so as to keep optical slant constant while varying viewing distance. Even if we find effects of viewing distance on perceived aspect ratio on level ground, such effects might be reduced relative to those on hills. Indeed, because such a circumstance would maximize the difference between the hypothesized gaze estimate from gaze declination and from other sources (such as texture and stereo) that specify optical slant, we have more basis to expect mean differences between hill and ground conditions. That is, with low slants, viewed at far distances, we could be more confident that an influence of

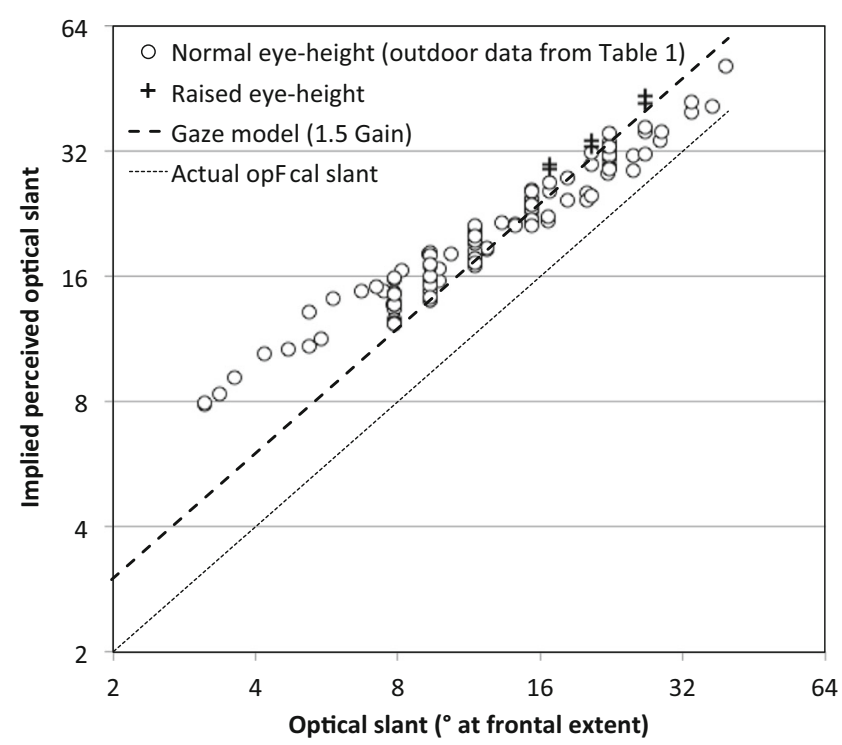

Fig. 5 Data from the outdoor studies in Table 1 interpreted in terms of the implied perceived optical slant. Dashed line representing an angular gain of 1.5 is also shown. Such a gain would be consistent with perceived angular declination as measured by multiple techniques (e.g., Durgin \& $\mathrm{Li}, 2011 \mathrm{~b})$

gaze information should lead to a difference in perceived optical slant inasmuch as the optical slant estimate on a surface with minimal slant is more divergent from the true optical slant.

\section{Experiment 2}

In Experiment 2, we examined a shallow optical slant $\left(6^{\circ}\right)$, for which prior studies of slant perception suggest that distance effects on perceived slant would be particularly prominent $(\mathrm{Li}$ \& Durgin, 2010, 2013). If perceived aspect ratios on level ground are different from perceived aspect ratios on a hill, then the difference should be easiest to detect in shallow slants viewed at a distance.

\section{Method}

Participants Seventeen undergraduate students from Swarthmore College participated in this experiment for pay (a scheduling anomaly caused there to be 17 rather than 16 participants). All participants had normal or corrected-tonormal vision. None had participated in Experiment 1.

Environments The experiment was conducted in three outdoor fields located in the campus of Swarthmore College, including a large $6^{\circ}$ hill (which was approximately planar in the testing area); a large, level, open field' and a level platform (the grassy stage of the Swarthmore College amphitheater) $1.2 \mathrm{~m}$ higher than the adjacent ground (see Fig. 6). All the fields were covered with short grass. The aspect ratio stimuli consist 
A

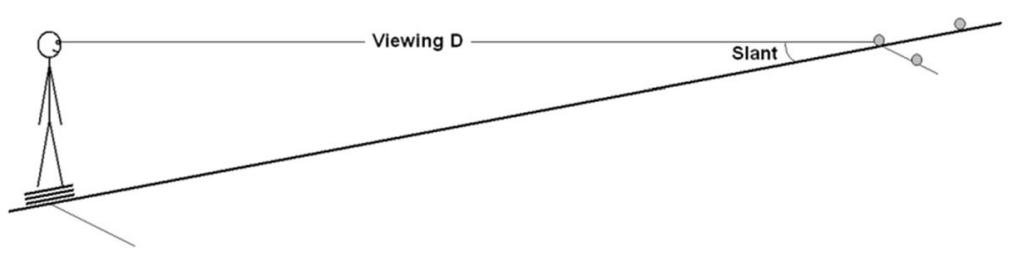

B

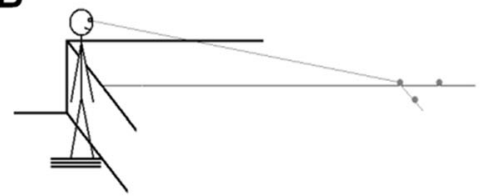

C

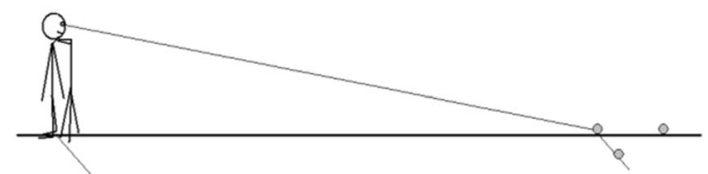

Fig. 6 Diagram depicting the environments used in Experiment 2. The experiment was conducted on a large $6^{\circ}$ hill (a), a level stage of an amphitheater (b), and a large, level, open field where participants either stood or kneeled to obtain two different eye heights (c)

of three white foam balls. The size of the foam balls was scaled to the viewing distance so that the retinal size was fixed at $0.5^{\circ}$. The frontal extent of the $\mathrm{L}$ shape was also scaled to viewing distance, with a retinal size of about $7.2^{\circ}$. The three balls were either presented on the level surfaces or on the hill surface. Four viewing distances $(5.74,9.57,13.39$, and 17.22 $\mathrm{m}$, corresponding to eye heights of $0.6,1.0,1.4$, and $1.8 \mathrm{~m}$ ) were examined in the level-surface condition by adjusting the participant's eye height relative to the level surface (with the help of a chin rest on a tripod, and adjustable pads underfoot), while keeping the optical slant fixed at $6^{\circ}$. For practical reasons, only the farthest viewing distance $(17.14 \mathrm{~m})$ was tested in the hill-surface condition, in which the gaze direction was horizontal but the optical slant was also $6^{\circ}$.

Design and procedure A within-subjects design was used. Each participant gave verbal estimates of aspect ratios in both hill and level-ground conditions at an optical slant of $6^{\circ}$. One hill condition (viewed from $17.14 \mathrm{~m}$ ) and four level-ground conditions (with viewing distances of 5.74, 9.57, 13.39, and $17.22 \mathrm{~m}$ ) were examined. The order of the conditions was randomized and was counterbalanced across participants. In each condition, five consecutive trials of verbal estimation of the perceived aspect ratio were collected. The actual aspect ratio of the first three trials was predetermined. In the first trial, the in-depth to frontal ratio was randomly chosen from $2.0,3.0$, or 4.0 . The aspect ratios in the second and third trials were always 1.0 and 5.0, with half of the participants shown the 1.0 ratio first and the other half shown the 5.0 ratio first. The aspect ratio in the fourth trial was calculated from the participants' first three estimates (using Equation 1), so that the ratio would match the perceived 1:1 ratio of that participant. The aspect ratio in the fifth trial was calculated based on all four former estimates to match the participant's perceived 1:1 ratio.

\section{Results}

The mean ratio of aspect ratios (physical ratio/estimated ratio) of the five trials in each testing condition was calculated for each participant. The mean RARs across participants are plotted for the five testing conditions separately in Fig. 7. It is clear that the RARs increased with viewing distance in the levelground condition. A one-way within-subjects analysis of variance (ANOVA) was conducted on the aspect ratio data of the level-ground condition. A significant main effect was found for viewing distance, $F(3,48)=19.46, p<.0001, \eta^{2} .047$. A paired $t$ test conducted on the aspect ratio data in the farthest viewing distance found no reliable difference between the level-ground condition $(M=2.94, S E=0.36)$, and the hill condition $(M=2.85, S E=0.31), t(16)=1.257, p=.227$. (Nor was there any reduction in variance for the level surface relative to the hill.)

\section{Discussion}

Experiment 2 examined a shallow optical slant $\left(6^{\circ}\right)$ with different viewing distances. We observed a significant distance effect on the ratio of aspect ratio (physical ratio/estimated ratio), which indicated that perceived optical slant was clearly affected by viewing distance even on level ground. This is

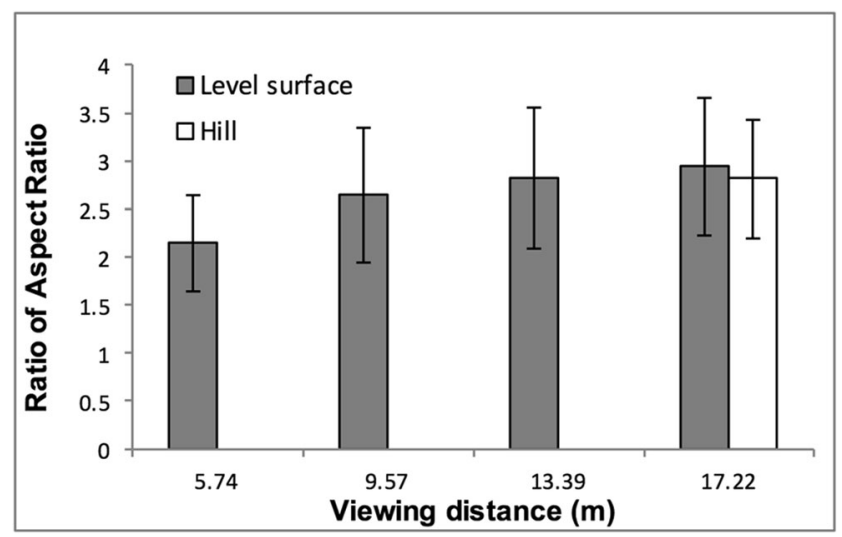

Fig. 7 Results of Experiment 2. The mean ratio of aspect ratio (physical ratio/estimated ratio) across all the participants is plotted as a function of viewing distance and surface condition (level surface vs. hill). Error bars represent $95 \%$ confidence intervals 
different from perceived angular declination, which is largely invariant with viewing distance. Moreover, with the shallow optical slant $\left(6^{\circ}\right)$, the slant gain becomes much larger (2.0 to 3.0) than the 1.5 gain observed in perceived angular declination (e.g., to targets on a grassy field; Durgin \& Li, 2011b, Expt. 1). These results suggest that the perceptual function of optical slant along level ground is different from that of angular declination, at least for small optical slants. Most important, for the farthest ground surface and hill surface, where the discrepancy between the observed optical slant ratio $(\sim 2.9)$ and the 1.5 gain predicted by the angular declination model was greatest, the observed slant ratio on the ground was essentially identical to that on the hill. Combining the results of Experiments 1 and 2, the present findings strongly suggest that angular declination is not used by the visual system to determine the optical slant along level ground, even though it is a potentially reliable source of relevant information.

In passing, we note that the implicitly measured exaggeration of perceived optical slant observed here for a shallow hill is very similar to the overestimation found for explicit verbal reports of hill slants (i.e., the aspect ratio results indicate that the $6^{\circ}$ hill was perceived as being about $17^{\circ}$ ), yet did not differ between hills and level ground. Although our study was not intended to address this issue, this does seem to cast doubt on theories of hill-slant exaggeration based on energy expenditure (e.g., Proffitt et al., 1995; see also Durgin et al., 2009).

\section{General discussion}

In the present study, we examined whether angular declination information contributes to perceived optical slant on level ground. We employed the aspect ratio task as an implicit measure to assess perceived optical slant (following Li \& Durgin, 2010). The aspect ratio data in the level-ground condition were compared with that in the hill condition, where angular declination information was irrelevant. Even when there was a large discrepancy between the angular gain expected from gaze declination and the angular exaggeration observed for a shallow, distant hill, no difference was observed in the matched level-ground case. This strongly suggests that angular declination does not contribute to the estimation of optical slant on level ground.

The present results are somewhat surprising because we might have expected that perceived aspect ratio on level ground would be more accurate than that on a hill. As Gibson (1950) pointed out, the ground plane is important to visual space perception of terrestrial animals. It has been observed that many visual cues of the spatial layout may rely on the presence of a level ground. For example, angular declination (also known as the slope of regard or height in the field) only works as an absolute egocentric distance cue when the target is on level ground (Ooi et al., 2001; Wallach \& O’Leary,
1982). Consistent with the idea that the ground plane is special, several studies have shown that the ground plane dominates the ceiling in the spatial layout perception (Bian, Braunstein, \& Andersen, 2005, 2006; Kavšek \& Granrud, 2013), and perceived exocentric distance was also less biased when targets were on the ground than when they were attached on the ceiling (Bian \& Anderson, 2011).

A theoretical advantage of level ground over a hill, for perceiving optical slant, is that the $\left(0^{\circ}\right)$ geographical slant of the ground plane carries information so that once angular declination is known, optical slant can be calculated. Knowing the geographical slant of the ground would be particularly useful in determining optical slant. However, the present finding that perceived angular declination does not contribute to perceived optical slant (at least for small optical slants) suggests that perceived geographical slant of the ground is a highorder perceptual variable, whereas the perceived optical slant and perceived angular declination are low-order (earlier, or more primitive) perceptual variables. Low-order variables are presumed to be used by the visual system to compute high-order variables. Indeed, for the visual system, knowing the geographic orientation of the ground plane is quite important because it is directly relevant to locomotion (or plan of locomotion) along the ground. Determining the geographical slant of a surface requires an external reference frame (such as that provided by angular declination, and the implicit horizon). In contrast, several visual cues (e.g., binocular disparity and texture cues) can be used to determine optical slant, which is defined relative to the direction of observation.

The geographical slant of a surface seems to be what we consciously experience. This accessibility to consciousness presumably makes perceived geographical slant more stable and robust across different viewing conditions (i.e., slant constancy), which would be very important for maintaining a rigid representation of the environment during navigation. Indeed, participants have been found to be better at discriminating geographical slant than optical slant (Sedgwick \& Levy, 1985). When observers were asked to give explicit judgment about geographical slants, their estimates were fairly robust (i.e., with similar bias functions) even when the angular declination was quite different (Durgin, Li, \& Hajnal, 2010b). However, the more rigid and robust perception of geographical slant over optical slant does not imply that perceived geographical slant is computed prior to perceived optical slant-it may instead signify that optical slant, per se, is simply not readily accessible to consciousness.

Gibson (1950) proposed that space perception is based on the optic array. Both angular declination and optical slant involve optical information contained in the optic array. It is possible that perceived geographical slant is computed from perceived optical slant and perceived angular declination. $\mathrm{Li}$ and Durgin (2009) found that the perceived geographical slant of a large downhill surface changed with the distance between 
the observer and the edge of the downhill slope (i.e., a steep downhill slant appears shallower from nearer the edge of the slope). They also showed that this failure of constancy in perceived geographical slant could be explained quantitatively by assuming that the perceived downhill slope is quantitatively consistent with combination of perceived angular declination and perceived optical slant.

We note that the mismatch between perceived angular declination and perceived optic slant for small optical slants at a distance means that the perceived geographical slant of a level ground plane may tend to be nonzero in the distance where optic slant is low, and viewing distance is high. This observation is consistent with the phenomenology used by $\mathrm{Wu}$ et al. (2004) to argue for their intrinsic bias hypothesis, but provides an alternative explanation in terms of optical slant rather than geographical slant.

In conclusion, the present findings suggest that perceived angular declination does not contribute to the perception of optical slant on level ground. This independence of these two optical variables can be understood as reflecting an unwillingness to assume a level-ground plane. After all, detecting ground-plane deviations from horizontal probably requires that the system not assume that the ground plane is horizontal. Rather, the visual system may rely on two other optical variables (angular declination and optical slant) to compute a higher order perceptual variable-geographical slant. Detecting deviation of the ground from horizontal is critical for the planning and control of motor action - which may be why geographical slant is more accessible to awareness than is optical slant.

Acknowledgements This research was supported by Award R15EY021026 from the National Eye Institute and by Grant 31671129 from the National Natural Science Foundation of China. The content is solely the responsibility of the authors and does not necessarily represent the official views of the National Eye Institute or the National Institutes of Health.

\section{References}

Adams, W. J., Elder, J. H., Graf, E. W., Leyland, J., Lugtigheid, A. J., \& Muryy, A. (2016). The Southampton-York Natural Scenes (SYNS) dataset: Statistics of surface attitude. Scientific Reports, 6, 35805.

Beck, J., \& Gibson, J. J. (1955). The relation of apparent shape to apparent slant in the perception of objects. Journal of Experimental Psychology, 50, 125-133.

Beusmans, J. M. (1998). Optic flow and the metric of the visual ground plane. Vision Research, 38, 1153-1170.

Bian, Z., \& Andersen, G. J. (2011). Environmental surfaces and the compression of perceived visual space. Journal of Vision, 11(7), 4. doi: https://doi.org/10.1167/11.7.4

Bian, Z., Braunstein, M. L., \& Andersen, G. J. (2005). The ground dominance effect in the perception of 3-D layout. Attention, Perception, \& Psychophysics, 67, 802-815.

Bian, Z., Braunstein, M. L., \& Andersen, G. J. (2006). The ground dominance effect in the perception of relative distance in 3-D scenes is mainly due to characteristics of the ground surface. Perception \& Psychophysics, 68, 1297-1309.

Bridgeman, B., \& Hoover, M. (2008). Processing spatial layout by perception and sensorimotor interaction. The Quarterly Journal of Experimental Psychology, 61, 851-859.

Cutting, J. E., \& Millard, R. T. (1984). Three gradients and the perception of flat and curved surfaces. Journal of Experimental Psychology: General, 113, 198-216.

Durgin, F. H., Baird, J. A., Greenburg, M., Russell, R., Shaughnessy, K., \& Waymouth, S. (2009). Who is being deceived? The experimental demands of wearing a backpack. Psychonomic Bulletin \& Review, 16, 964-969.

Durgin, F. H. Hajnal, A., Li, Z., Tonge, N., \& Stigliani, A. (2010a). Palm boards are not action measures: An alternative to the two-systems theory of geographical slant perception. Acta Psychologica, 134, 182-197.

Durgin, F. H., \& Li, Z. (2011a). The perception of 2D orientation is categorically biased. Journal of Vision, 11(8), 13. https://doi.org/ 10.1167/11.8.13

Durgin, F. H., \& Li, Z. (2011b). Perceptual scale expansion: An efficient angular coding strategy for locomotor space. Attention, Perception, \& Psychophysics, 73, 1856-1870.

Durgin, F. H., Li, Z., \& Hajnal, A. (2010b). Slant perception in near space is categorically biased: Evidence for a vertical tendency. Attention, Perception, \& Psychophysics, 72, 1875-1889.

Epstein, W., Bontrager, H., \& Park, J. (1962). The induction of nonveridical slant and the perception of shape. Journal of Experimental Psychology, 63, 472-479.

Gibson, J. J. (1950). The perception of the visual world. Boston: Houghton Mifflin.

Gibson, J. J., \& Cornsweet, J. (1952). The perceived slant of visual surfaces-Optical and geographical. Journal of Experimental Psychology, 44(1), 11-15.

Gilinsky, A. S. (1951). Perceived size and distance in visual space. Psychological Review, 58, 460-482. https://doi.org/10.1037/ h0061505.

Kavšek, M., \& Granrud, C. E. (2013). The ground is dominant in infants' perception of relative distance. Attention, Perception, \& Psychophysics, 75, 341-348.

Koffka, K. (1935). Principles of gestalt psychology. New York: Harcourt Brace.

Kudoh, N. (2005). Dissociation between visual perception of allocentric distance and visually directed walking of its extent. Perception, 34 , $1399-1416$.

Li, Z., \& Durgin, F. H. (2009). Downhill slopes look shallower from the edge. Journal of Vision, 9(11), 6. https://doi.org/10.1167/9.11.6

Li, Z., \& Durgin, F. H. (2010). Perceived slant of binocularly viewed largescale surfaces: A common model from explicit and implicit measures. Journal of Vision, 10(14), 13. https://doi.org/10.1167/10.14.13

Li, Z., \& Durgin, F. H. (2011). Design, data and theory regarding a digital hand inclinometer: A portable device for studying slant perception. Behavior Research Methods, 43, 363-371

Li, Z., \& Durgin, F. H. (2012). Manual matching of perceived surface orientation is affected by arm posture: Evidence of calibration between proprioception and visual experience in near space. Experimental Brain Research, 216, 299-309.

Li, Z., \& Durgin, F. H. (2013). Depth compression based on mis-scaling of binocular disparity may contribute to angular expansion in perceived optical slant. Journal of Vision, 13(12), 3. https://doi.org/10. $1167 / 13.12 .3$

Li, Z., Phillips, J., \& Durgin, F. H. (2011). The underestimation of egocentric distance: Evidence from frontal matching tasks. Attention, Perception, \& Psychophysics, 73, 2205-2217.

Loomis, J. M., Da Silva, J. A., Fujita, N., \& Fukusima, S. S. (1992). Visual space perception and visually directed action. Journal of 
Experimental Psychology: Human Perception and Performance, 18, 906-921.

Loomis, J. M., \& Philbeck, J. W. (1999). Is the anisotropy of perceived 3D shape invariant across scale?. Attention, Perception, \& Psychophysics, 61, 397-402.

Loomis, J. M., Philbeck, J. W., \& Zahorik, P. (2002). Dissociation between location and shape in visual space. Journal of Experimental Psychology: Human Perception and Performance, 28(5), 1202 1212.

Messing, R. M., \& Durgin, F. H. (2005). Distance perception and the visual horizon in head-mounted displays. ACM: Transactions on Applied Perception, 2, 234-250.

Ooi, T. L., Wu, B., \& He, Z. J. (2001). Distance determined by the angular declination below the horizon. Nature, 414, 197-200.

Philbeck, J. W. (2000). Visually directed walking to briefly glimpsed targets is not biased toward fixation location. Perception, 29, 259 272.

Proffitt, D. R., Bhalla, M., Gossweiler, R., \& Midgett, J. (1995). Perceiving geographical slant. Psychonomic Bulletin \& Review, 2, 409-428.

Rogers, B. J., \& Bradshaw, M. F. (1993). Vertical disparities, differential perspective and binocular stereopsis. Nature, 361(6409), 253.
Sedgwick, H. A. (1986). Space perception. In K. R. Boff, L. Kaufman, \& J. P. Thomas (Eds.). Handbook of perception and human performance (pp. 21.1-21.57). New York: John Wiley.

Sedgwick, H. A., \& Levy, S. (1985). Environment-centered and viewercentered perception of surface orientation. Computer Vision, Graphics, and Image Processing, 31, 248-260.

Shaffer, D. M., McManama, E., Swank, C., Williams, M., \& Durgin, F. H. (2014). Anchoring in action: Manual estimates of slant are powerfully biased toward initial hand orientation and are correlated with verbal report. Journal of Experimental Psychology: Human Perception and Performance, 40, 1203.

Tyler, C. W. (1991). The horoptor and binocular fusion. In D. Regan (Ed.), Binocular Vision (pp. 19-37). Boca Raton: CRC Press.

von Helmholtz, H. L. (1866). Handbuch der Physiologische Optik [Handbook of physiological optics]. Hamburg: Voss.

Wallach, H., \& O'Leary, A. (1982). Slope of regard as a distance cue. Perception \& Psychophysics, 31, 145-148.

Williams, M. J. C., \& Durgin, F. H. (2015). Direct manipulation of perceived angular declination affects perceived size and distance: A replication and extension of Wallach and O'Leary (1982). Attention, Perception, \& Psychophysics, 77, 1371-1378.

Wu, B., Ooi, T. L., \& He, Z. J. (2004). Perceiving distance accurately by a directional process of integrating ground information. Nature, 428(6978), 73-77. 